\title{
Gastric Anastomotic Leak, CTCAE
}

National Cancer Institute

\section{Source}

National Cancer Institute. Gastric Anastomotic Leak, CTCAE. NCI Thesaurus. Code C143498.

A finding of leakage due to breakdown of a gastric anastomosis (surgical connection of two separate anatomic structures). 